\title{
Dual-Level Afferent Control of Growth Hormone-Releasing Hormone (GHRH) Neurons in GHRH-Green Fluorescent Protein Transgenic Mice
}

\author{
Nelly Baccam, ${ }^{1}$ Gérard Alonso, ${ }^{1}$ Thomas Costecalde, ${ }^{1}$ Pierre Fontanaud, ${ }^{1}$ François Molino, ${ }^{1}$ Iain C. A. F. Robinson, ${ }^{2}$ \\ Patrice Mollard, ${ }^{1}$ and Pierre-François Méry ${ }^{1}$ \\ 'Département d'Endocrinologie, Institut de Génomique Fonctionnelle, Institut National de la Santé et de la Recherche Scientifique U661, Centre National de \\ la Recherche Scientifique UMR 5203, Université Montpellier 1, Université Montpellier 2, 34094 Montpellier, France, and ²Division of Molecular \\ Neuroendocrinology, National Institute for Medical Research, The Ridgeway, Mill Hill, London NW7 1AA, United Kingdom
}

The organization of the peptidergic neurons of the hypothalamic arcuate nucleus is not fully understood. These include growth hormonereleasing hormone (GHRH) neurons involved in growth and metabolism. We studied identified GHRH neurons of GHRH-green fluorescent protein transgenic mice using patch-clamp methods and focused on gender differences, which govern the physiological patterns of GHRH release. Both the spontaneous firing rates and the intrinsic properties of GHRH neurons were similar in males and females, although higher glutamatergic currents were noticed in females. Surprisingly, marked gender differences in GHRH neuronal activity were observed in response to the muscarinic agonist carbachol (CCh). In females, CCh enhanced action potential firing in all GHRH neurons. In males, $\mathrm{CCh}$ enhanced action potential firing in two-thirds of GHRH neurons, whereas it decreased firing in the remainders. $\mathrm{M}_{1}$ agonist McN-A343 (10 $\mu \mathrm{M})$ mimicked, and $\mathrm{M}_{1}$ antagonist pirenzepine $(3 \mu \mathrm{M})$ blocked the effects of $\mathrm{CCh}$. In both genders, $\mathrm{CCh}$ did not change the intrinsic properties of GHRH neurons, although it strongly increased the frequency of glutamatergic currents, in the presence or absence of tetrodotoxin. In males only, CCh enhanced the frequency of GABAergic currents, and this modulation was antagonized by tetrodotoxin. Thus, the muscarinic regulation involved differential control of afferent inputs at short and long distances in male and female mice. The dual-level control could be a mechanism whereby the selective modulation of the GHRH system (short-distance control) is adjusted to the integrated regulation of arcuate nucleus activity (long-distance control).

Key words: acetylcholine; action potential; GABA; glutamate; patch clamp; growth hormone

\section{Introduction}

The arcuate nucleus receives varying hormonal messages, metabolic signals, and inputs from numerous brain structures. It controls basic body functions, such as growth, metabolism, appetite, and sexual maturation. Among neuropeptides that encode arcuate nucleus functions, growth hormone-releasing hormone (GHRH), has a central role throughout lifespan, in growth and body homeostasis (Giustina and Veldhuis, 1998; Müller et al., 1999). Constitutive decreases in GHRH secretion and/or mutations inducing a loss-of-function of GHRH receptors elicit dwarfism (Gaylinn et al., 1999; Alba and Salvatori, 2004; Le Tissier et al., 2005).

Insights into the activity of GHRH neurons can only be ob-

\footnotetext{
Received Nov. 30, 2005; revised Nov. 21, 2006; accepted Dec. 31, 2006.

This work was supported by grants from Fondation pour la Recherche Médicale, Région Languedoc-Roussillon, and the UK Medical Research Council (ICAFR). We thank Doctors M. G. Desarmenien, N. Guerineau, J. M. Israel, and J. Epelbaum for helpful comments, A. Martin for sharing unpublished data, M. N. Mathieu for mice genotyping, and A. Delalbre and E. Gavois at the IFR3 animal facility.

Correspondence should be addressed to Pierre-François Méry, Département d'Endocrinologie, Institut de Génomique Fonctionnelle, 141 rue de la Cardonille, 34094 Montpellier Cedex 5, France. E-mail: pierre-francois.mery@igf.cnrs.fr.

DOI:10.1523/JNEUROSCI.2693-06.2007

Copyright $\odot 2007$ Society for Neuroscience $\quad$ 0270-6474/07/271631-11\$15.00/0
}

tained from electrophysiology, but this has proved elusive so far because of the inability to distinguish GHRH neurons from other populations of arcuate cells. Furthermore, GABAergic and glutamatergic inputs to the GHRH system, implicated indirectly from effects on GH release, have not yet been studied directly at the hypothalamic GHRH level (Giustina and Veldhuis, 1998; Gonzalez et al., 1999; Müller et al., 1999; Pinilla et al., 1999). How these transmitters regulate GHRH neurons is of considerable interest, because data related to feeding circuits showed that GABAergic and glutamatergic neurons play a central role in the organization of arcuate nucleus activity (Horvath and Diano, 2004; Sternson et al., 2005). Also, the modulation of GABAergic and glutamatergic neurotransmissions is necessary to finely tune arcuate neuronal activity to body status (Horvath and Diano, 2004). So far, only few factors were demonstrated to regulate directly GHRH secretion, and these include acetylcholine, which triggers GHRH secretion and induces GH release (Magnan et al., 1993; Giustina and Veldhuis, 1998; Rigamonti et al., 1998; Müller et al., 1999). However, the mode of action of these neuromodulators is not understood, namely during the highly ordered bursts of GH secretion occurring in the adulthood. Moreover, GH bursts and GHRH release are well known to exhibit gender differences (Giustina and Veldhuis, 1998; Jaffe et al., 1998, 2002; Müller et al., 
1999). The steady-state GH secretion is higher and secretory peaks are less organized, and often weaker, in females. Mechanisms involved in GH secretion have been proposed, and they involve intermittent GHRH and somatostatin (SRIH) releases (Wagner et al., 1998; Farhy et al., 2001, 2002; MacGregor and Leng, 2005; Veldhuis et al., 2005). However, SRIH levels do not always correlate with the pulsatile release of GH (Giustina and Veldhuis, 1998; Dimaraki et al., 2001, 2003), and SRIH alone does not support gender differences in growth (Low et al., 2001; Zheng et al., 1997; Kreienkamp et al., 1999). Thus, other factors are playing major roles in the physiological organization of GHRH neuronal activity and its gender difference.

Here, we studied how identified GHRH neurons worked and responded to the muscarinic agonist, carbachol, in acute brain slices from both adult male and female GHRH-green fluorescent protein (GFP) mice (Balthasar et al., 2003). Strikingly, carbachol revealed a gender difference in the control of GHRH neuronal activity, which involved fine tuning of afferent inputs at both short and long distances from the GHRH neurons.

\section{Materials and Methods}

Histology and immunocytochemistry. Mice, under deep anesthesia with equithesin, were perfused through the ascending aorta with PBS, pH 7.4 $(20 \mathrm{ml})$, followed by $4 \%$ paraformaldehyde and $0.5 \%$ glutaraldehyde in $0.1 \mathrm{M}$ phosphate buffer, pH $7.4(100 \mathrm{ml})$. Brains were quickly dissected and postfixed by immersion in $4 \%$ paraformaldehyde $(24-48 \mathrm{~h})$. The forebrain portions including the hypothalamus were cut with a vibratome into 40 - to $50-\mu \mathrm{m}$-thick frontal sections that were either used for direct observation of enhanced GFP (eGFP) fluorescence or treated for fluorescence immunocytochemistry.

Antibodies used included a rabbit polyclonal antibody against eGFP (diluted 1:2000; Invitrogen, Eugene, OR), a guinea pig polyclonal antibody against vesicular glutamate transporter 2 (VGLUT2; diluted 1:2000; Millipore, Temecula, CA), a goat polyclonal antibody against vesicular acetylcholine transporter (VACht; diluted 1:2000; Millipore), and a mouse monoclonal antibody against GABA (diluted 1:2000; Millipore). After rinsing in PBS, sections were incubated with either one or two primary antibodies diluted in PBS containing $1 \%$ BSA, $1 \%$ normal goat serum, and $0.1 \%$ Triton $\mathrm{X}-100\left(48 \mathrm{~h}, 4^{\circ} \mathrm{C}\right)$. After additional rinsing in PBS, sections were incubated $\left(2 \mathrm{~h}, 4^{\circ} \mathrm{C}\right)$ with the corresponding secondary antibodies conjugated with either cyanine 3 (Cy3) (Jackson ImmunoResearch, Newmarket, UK) or Alexa 488 (Invitrogen). The secondary antibodies were diluted 1:2000 in PBS containing 1\% normal goat serum and $0.1 \%$ Triton X-100.

After rinsing, sections were mounted in Mowiol and observed under a Bio-Rad (Hercules, CA) MRC 1024 confocal laser scanning microscope equipped with a krypton/argon mixed gas laser. Two laser lines emitting at 488 and $568 \mathrm{~nm}$ were used for exciting the Alexa-Fluor 488- and Cy3-conjugated secondary antibodies, respectively. The background noise of each confocal image was reduced by averaging five image inputs. The organization of the immunostained structures was studied on single confocal images of 1-2 $\mu \mathrm{m}$. Unaltered digitalized images were transferred to a computer and processed with Adobe (San Jose, CA) Photoshop.

Slice preparation for electrophysiological recording. Female (13.6 \pm 0.3 weeks, $n=79)$ and male (13.6 \pm 0.3 weeks, $n=87)$ GHRH-GFP mice (Balthasar et al., 2003) were anesthetized by isofluorane inhalation, killed by decapitation, and brains quickly removed into cold $\left(0-2^{\circ} \mathrm{C}\right)$ solution 1 [containing the following (in $\mathrm{mm}$ ): $92 \mathrm{NMDG}-\mathrm{Cl}, 2.3 \mathrm{KCl}, 1 \mathrm{CaCl}_{2}, 6$ $\mathrm{MgCl}_{2}, 26 \mathrm{NaHCO}_{3}, 1.2 \mathrm{KH}_{2} \mathrm{PO}_{4}, 25$ glucose, 0.2 ascorbic acid, 0.2 thiourea, $\mathrm{pH} 7.4$, gassed with $95 \% \mathrm{CO}_{2}, 5 \% \mathrm{O}_{2}$ ]. Sagittal sections $(300 \mu \mathrm{m})$ were cut with a microtome (Integraslice 7550; Campden, Loughborough, UK) and stored at $34^{\circ} \mathrm{C}$ in solution 2 [containing the following (in $\mathrm{mm}$ ): $115 \mathrm{NaCl}, 2.5 \mathrm{KCl}, 1 \mathrm{CaCl}_{2}, 4 \mathrm{MgCl}_{2}, 26 \mathrm{NaHCO}_{3}, 1.25 \mathrm{NaH}_{2} \mathrm{PO}_{4}$, 25 glucose, 0.2 ascorbic acid, 0.2 thiourea, $\mathrm{pH} 7.4$, gassed with $95 \% \mathrm{CO}_{2}$, $5 \% \mathrm{O}_{2}$ ] for at least $45 \mathrm{~min}$.

In some experiments, vaginal smears were obtained from isoflourane- anesthetized female mice by flushing the vagina 2-3 times with $35 \mu \mathrm{l}$ of $0.9 \%$ saline. This was immediately placed onto a slide and examined to determine the phase of the estrous cycle.

Patch-clamp recordings. Slices were immobilized with a nylon grid in a submersion chamber on the stage of an upright microscope (Axioskop FS2; Zeiss, Oberkochen, Germany) and superfused with solution 3 [containing the following (in mM): $125 \mathrm{NaCl}, 2.5 \mathrm{KCl}, 2 \mathrm{CaCl}_{2}, 1 \mathrm{MgCl}_{2}, 26$ $\mathrm{NaHCO}_{3}, 1.25 \mathrm{NaH}_{2} \mathrm{PO}_{4}, 12$ glucose, $\mathrm{pH}$ 7.4, gassed with $95 \% \mathrm{CO}_{2}, 5 \%$ $\mathrm{O}_{2}$ ] at a rate of $\sim 1.5 \mathrm{ml} / \mathrm{min}$ for at least $15 \mathrm{~min}$ at $30-32^{\circ} \mathrm{C}$. They were viewed with a $63 \times$ immersion objective and Nomarski differential interference contrast optics. Infrared differential interference contrast illumination was used to visualize neurons deeper in the slices and the images were captured with an infrared camera (C2400; Hamamatsu Photonics, Massy, France). Borosilicate glass pipettes $(6-8 \mathrm{M} \Omega$ ) were connected to the head stage of an EPC-9/2 amplifier (HEKA, Lambrecht, Germany) to acquire and store data using Pulse 8.09 software. Agonists were bathapplied, and solutions were changed by switching the supply of the perfusion system from one to another. Activity was recorded for at least 4 min at steady state under each condition. In some experiments, transient bolus applications of agonists were used. Known amounts of agonists were diluted in a small $(20 \mu \mathrm{l})$ volume of control solution, and ejected with a pipette into the constant flow of the perfusion, at a distance $\sim 2 \mathrm{~cm}$ upstream from the brain slice. The lag required to reach the slice was determined by bolus injections of $\mathrm{KCl}$, in the same experiments and was typically 60-120 s (data not shown).

Standard off-line detections of spontaneous events (action potentials or synaptic currents) were performed with Axograph 4.0 (Molecular Devices, Foster City, CA). In brief, a template was generated and used to scan the raw trace for similar waveforms. All matching events are stored and, when present, false positive events were discarded, either manually or automatically on the basis of their amplitude or kinetics. Other calculations and analysis were performed with IgorPro (Wavemetrics, Lake Oswego, OR).

For extracellular recordings of spontaneous action potentials, pipettes were filled with the following (in $\mathrm{mM}$ ): $130 \mathrm{NaCl}, 2.5 \mathrm{KCl}, 10 \mathrm{HEPES}, 10$ glucose, $2 \mathrm{CaCl}_{2}, 1 \mathrm{MgCl}_{2}, \mathrm{pH} 7.4$ with $\mathrm{NaOH}, 295$ mOsm adjusted with $\mathrm{NaCl}$. Once the tip of the pipette was positioned at the surface of a neuron, its activity was recorded in the voltage-clamp mode $(0 \mathrm{mV})$ of the loose-patch configuration (seal resistance $>50 \mathrm{M} \Omega$ ).

For whole cell recordings in voltage- or current-clamp configurations, pipettes were filled with the following (in $\mathrm{mm}$ ): $140 \mathrm{~K}$-gluconate, 10 HEPES, 3 EGTA acid form, $1 \mathrm{MgCl}_{2}$, $2 \mathrm{MgATP}$, pH 7.4 with $\mathrm{KOH}, 295$ mOsm adjusted with K-gluconate. Voltage was corrected for the junction potential of $\approx 10 \mathrm{mV}$ (Neher, 1992). Pipette and cell capacitances were fully compensated. Cell capacitances were $13.2 \pm 0.4 \mathrm{pF}(n=109)$ in males and $13.8 \pm 0.4 \mathrm{pF}(n=92)$ in females. Series resistance was lower than $30 \mathrm{M} \Omega$.

The resting membrane potential was the steady-state value recorded when neurons were held at $0 \mathrm{pA}$ in current-clamp mode. Action potential properties were examined in current-clamp mode by injecting current pulses of $50 \mathrm{~ms}$ duration at $1 \mathrm{~Hz}$. Current was set so that the interpulse potential was $-70 \mathrm{mV}$. Infrathreshold properties were also examined with this protocol, except that pulse duration was $200 \mathrm{~ms}$ at $0.2 \mathrm{~Hz}$. Steps in which synaptic activity occurred at the end of the pulse were not included in analysis. The current-voltage relationships at the end of the pulse were fitted to a linear equation with constant (voltage equals slope by current plus intercept) in their linear range (less than $-50 \mathrm{mV}$ ).

Spontaneous synaptic activity was recorded at constant potentials in voltage-clamp mode. GABAzine-sensitive synaptic currents were recorded at -10 or $-30 \mathrm{mV}$ (chloride ions equilibrium potential being $\approx-110 \mathrm{mV}$ ), whereas CNQX-sensitive synaptic currents were recorded at $-70 \mathrm{mV}$ (monovalent cations equilibrium potential being $\approx 20 \mathrm{mV}$ ).

Chemicals. Chemicals of the highest grade were from Sigma (L'isle d'Abeau, France) except Mowiol (Calbiochem, La Jolla, CA), D-glucose (Euromedex, Souffelweyersheim, France) and tetrodotoxin (Latoxan, Valence, France).

Statistics. In each experiment, the Kolmogorov-Smirnoff (KS) test was used to test the statistical difference between two distributions obtained at steady-state (typically in the absence and in the presence of an agonist). 

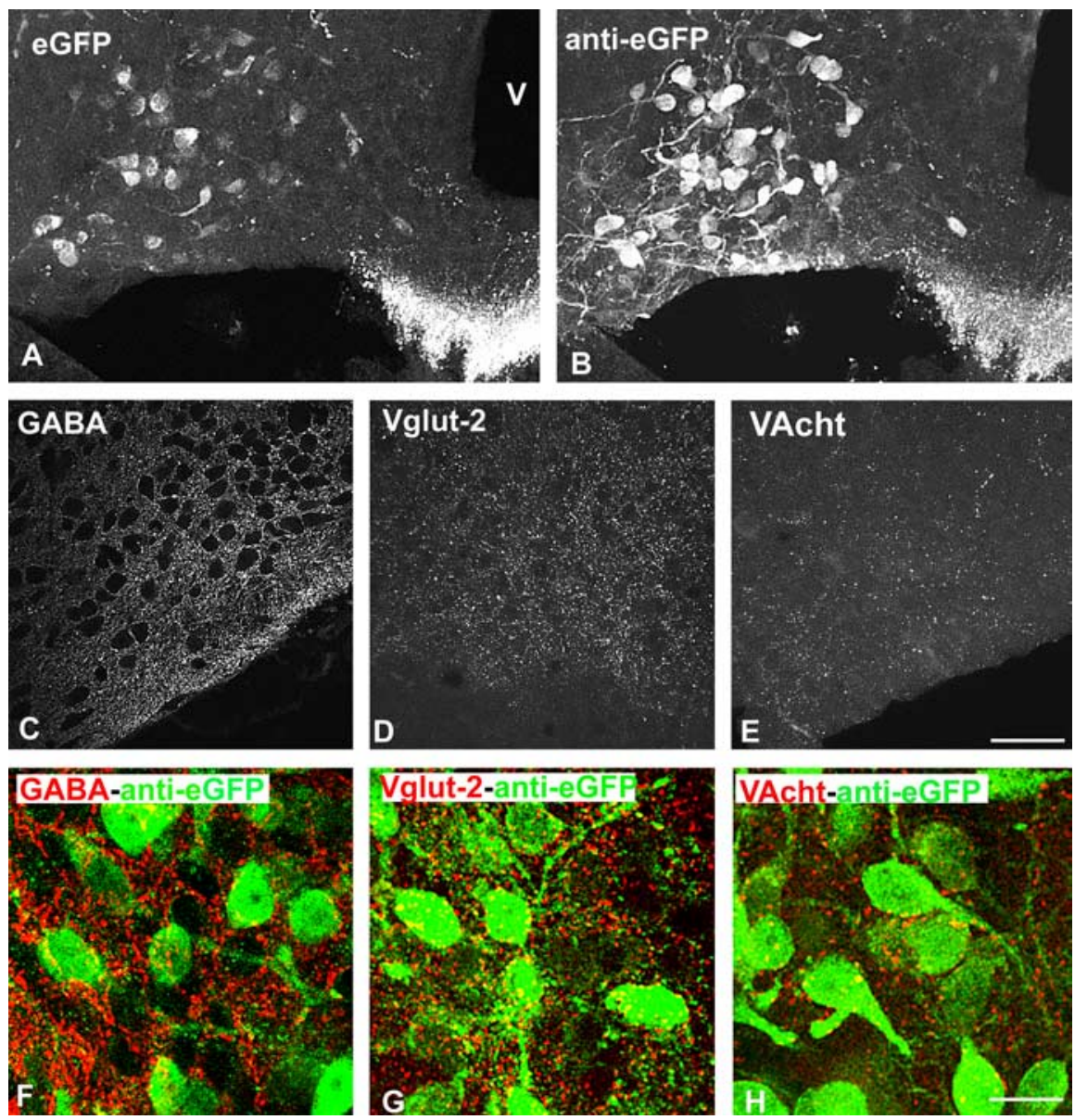

Figure 1. Visualization of GHRH neurons and their putative afferent fibers in the arcuate nucleus of GHRH-GFP mice. $\boldsymbol{A}, \boldsymbol{B}$, GHRH-GFP neurons before $(\boldsymbol{A})$ and after $(\boldsymbol{B})$ eGFP immunostaining. Pictures are taken from the same brain section. $\boldsymbol{C}-\boldsymbol{E}$, Immunocytochemical visualization of GABAergic (anti-GABA, $\boldsymbol{C}$ ), glutamatergic (anti-VGLUT2, D), and cholinergic (anti-VACht, $\boldsymbol{E}$ ) structures within the arcuate nucleus. Axon terminal-like structures are dispersed within the arcuate nucleus. $\boldsymbol{F}-\boldsymbol{H}$, Double immunocytochemical labeling of eGFP and of other neurotransmitters systems. eGFP-labeled cell bodies and dendritic-like processes are frequently surrounded by GABA- and VGLUT2-labeled axons, but only rarely by VACht-labeled axons. Pictures are from male mice. V, Third ventricle. Scale bars: (in $\boldsymbol{E}) \boldsymbol{A}-\boldsymbol{E}, 50 \mu \mathrm{m}$; (in $\boldsymbol{H}) \boldsymbol{F}-\boldsymbol{H}, 15 \mu \mathrm{m}$.

Data were then expressed as mean \pm SEM (see Figs. 2-8) and the averaged distributions were compared at each abscissa value with the appropriate statistical test to delineate the ranges of differences between distributions. A one-way ANOVA was used in comparing data pooled from independent experiments (i.e., male vs female comparisons), whereas paired comparisons between untreated and treated levels were evaluated using a paired Student $t$ test. When applicable, the KS test was also used when comparing the shapes of cumulated histograms (i.e., unpaired comparisons of data pooled from independent experiments). A value of $p<0.05$ was taken as significant.

Mean distributions are represented as lines connecting the mean values where symbols are the means and error bars are the SEM. For clarity, only part of the mean \pm SEM values are shown in the graphs.

\section{Results}

\section{Visualization of putative afferent inputs to}

\section{GHRH-GFP neurons}

Untreated sections of GHRH-GFP brains showed eGFP fluorescence associated with numerous neuronal cell bodies located in the arcuate nucleus and with axons located in the median eminence (Balthasar et al., 2003) (Fig. 1A). In sections immunostained for eGFP, intense staining was seen within all eGFP fluorescent structures located in the arcuate nucleus and the median eminence (Fig. 1 B). Compared with the eGFP fluorescence, how- ever, eGFP immunostaining always revealed one to three large dendritic-like structures associated with the labeled perikarya. No obvious gender differences were found in the number and organization of eGFP-labeled neuronal structures within the arcuate nucleus (data not shown).

Antibodies against VGLUT2, GABA, and VAChT were used to visualize the glutamatergic, GABAergic, and cholinergic systems, respectively (Fig. $1 C-H$ ). Immunostainings revealed essentially dotted axon terminal-like structures dispersed throughout the arcuate nucleus. The densities of either GABA- (Fig. 1C) or VGLUT2- positive (Fig. $1 D$ ) axon terminals were higher than that of VAChTpositive axons (Fig. $1 E$ ) in all sections studied, although no quantification was performed. Some sections were double immunostained for eGFP and for either GABA (Fig. $1 F$ ), VGLUT2 $(G)$ or VACht $(H)$. These suggested that eGFP-positive cell bodies and dendritic-like processes always appeared closely surrounded by GABA- or VGLUT2-positive terminal-like structures throughout the arcuate nucleus. In contrast, only scarce VAChT axons were detected around GFP-labeled neuronal cell bodies and dendrites. Again, no differences in the abundance of these structures were seen between male and female GHRH-GFP mice (data not shown).

Carbachol reveals a gender difference in the firing rate of GHRH-GFP neurons

We then recorded spontaneous action potentials from identified GHRH neurons in acute brain slices of GHRH-GFP transgenic mice using the loose-patch clamp configuration. The raw traces of Figure $2 A, B$ (taken from different experiments) illustrate that action potential firing was sustained, but could increase or decrease briefly. Despite these spontaneous variations, the instantaneous frequency of action potentials in a male GHRH-GFP neuron (Fig. $2 C$ ) was similar during the first $30 \mathrm{~s}(4.2 \pm 0.1 \mathrm{~Hz})$ and the last $30 \mathrm{~s}$ of the recording $(4.3 \pm 0.2 \mathrm{~Hz})$. This variability was also evident in recordings from female GHRH-GFP neurons (Fig. $2 D$ ), but again, the firing rate was similar during the first $(7.2 \pm 0.5 \mathrm{~Hz})$ and the last $30 \mathrm{~s}$ of the experiment $(6.8 \pm 0.3 \mathrm{~Hz})$. The results from such neuronal recordings, from 3 to $53 \mathrm{~min}$ (mean duration $952 \pm 48 \mathrm{~s}$ ) showed that the mean instantaneous frequency of spontaneous action potentials was similar in males $(3.6 \pm 0.5 \mathrm{~Hz}$ during the first $30 \mathrm{~s}$; $3.6 \pm 0.4 \mathrm{~Hz}$ during the last $30 \mathrm{~s} ; n=67)$ and females $(3.8 \pm 0.3$ $\mathrm{Hz}$ during the first $30 \mathrm{~s} ; 3.9 \pm 0.3 \mathrm{~Hz}$ during the last $30 \mathrm{~s} ; n=92)$. There were no evidently organized firing patterns, and in particular, action potentials were not clustered into repetitive bursts (see supplemental text, Fig. 1, available at www.jneurosci.org as supplemental material). The electrical activity was also analyzed as cumulative histograms summarizing the distributions of the instantaneous frequencies of action potentials (Fig. 2E). Under control conditions, most of the spontaneous activity ( $\sim 90 \%)$ 
occurred at $<10 \mathrm{~Hz}$, with a peak in the $2-3$ $\mathrm{Hz}$ range in male (diamonds) and female (squares) GHRH-GFP neurons, with no gender difference. However, because the activity of GHRH neurons in females might be influenced by their hormonal cycles, their stage of oestrus was also determined, and each action potential recording was classified accordingly. Interestingly, the distributions of the instantaneous frequencies of action potentials seemed to shift slightly toward the right as the cycle proceeded from diestrus, proestrus to estrus and metestrus, but this tendency did not reach statistical significance (Fig. $2 F$ ).

It has been reported that an acetylcholine mimetic stimulated GHRH secretion from the median eminence in sheep (Magnan et al., 1993), suggesting that the cholinergic system might alter the spontaneous activity of GHRH neurons to synchronize GHRH secretion. We therefore examined the effect of carbachol, a muscarinic agonist, on action potential firing in mouse GHRH-GFP neurons. The results of such an experiment (in a female) are shown Fig. 3A. After recording action potentials under control conditions, addition of $10 \mu \mathrm{M}$ carbachol (CCh) clearly increased the action potential firing rate. The mean action potential frequency was raised from $2.8 \mathrm{~Hz}$ under control conditions to $3.9 \mathrm{~Hz}$ in the presence of CCh. In females, the mean distribution of action potential frequency (Fig. $3 B$ ) under control conditions (triangles) was significantly shifted to the left in the presence of $10 \mu \mathrm{M} \mathrm{CCh}(n=11 ; 0.0005<p<0.05$ vs control, in the 0.25 to $20 \mathrm{~Hz}$ range) or $100 \mu \mathrm{M} \mathrm{CCh}(n=8 ; 0.005<p<0.05$ vs control, in the $1-13.5 \mathrm{~Hz}$ range).

Surprisingly, CCh induced either a stimulatory effect or an inhibitory effect on action potential firing in male GHRH-GFP neurons. An example of this inhibitory effect is shown in Fig. 3C, where $10 \mu \mathrm{M} C \mathrm{Ch}$ induced a strong reduction in the firing rate of a male GHRH-GFP neuron, from $7.3 \mathrm{~Hz}$ under control conditions to $3.8 \mathrm{~Hz}$ in the presence of $\mathrm{CCh}$. When the results from male GHRH-GFP neurons were pooled, CCh (10 and $100 \mu \mathrm{M})$ did not significantly modify the overall distribution of action potential firing rates (Fig. 3D), but a large variability was evident. The stimulatory and inhibitory effects of the muscarinic agonist $(10$ or $100 \mu \mathrm{M}$ ) were disassociated in Figure 3E. Female GHRHGFP neurons, where only stimulatory effects were recorded, clearly behaved differently from male GHRH-GFP neurons, where CCh had inhibitory effects in one-third of the experiments, and was most consistent at $100 \mu \mathrm{M}$ CCh (four of five neurons). Lower concentrations $(0.01,0.1$, and $1 \mu \mathrm{M})$ had no effects on action potential firing in GHRH-GFP neurons (data not shown). In some, but not all experiments, a washout period was allowed and the effects of 10-100 $\mu \mathrm{M}$ CCh were found reversible in females $(n=5)$ and males $(n=7)$ GHRH neurons. This reversibility was more readily demonstrated in experiments where CCh was quickly injected into the steady-state flow of the perfusion system. These bolus injections of CCh induced dose-dependent increases of the action potential firing rates in all females and
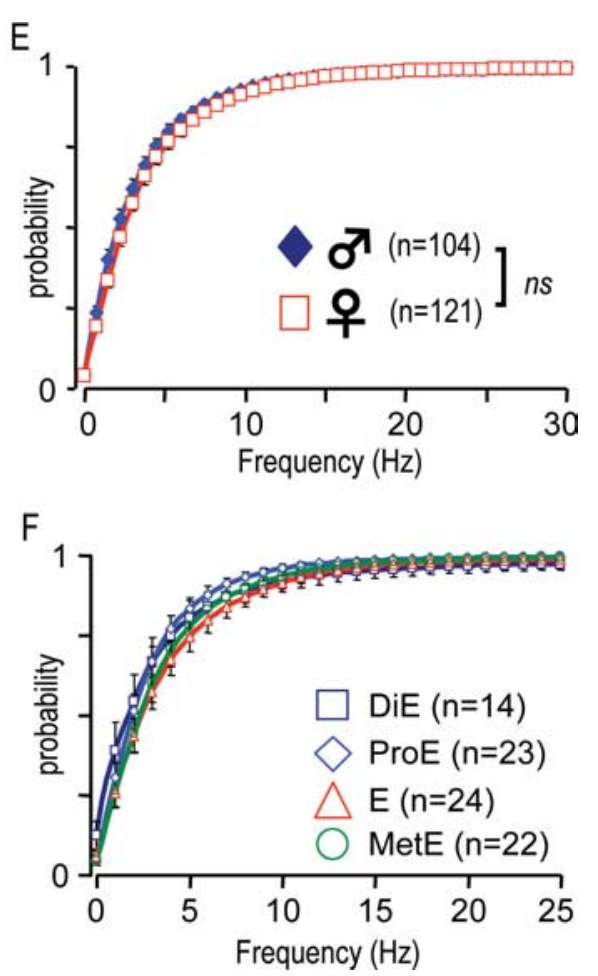

gure 2. The spontaneous electrical activity of GHRH-GFP neurons. $\boldsymbol{A}, \boldsymbol{B}$, Raw extracellular recordings performed in GHRH

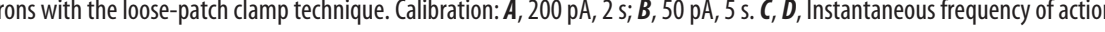
121) GHRH-GFP neurons, as well as in female GHRH-GFP neurons $(\boldsymbol{F})$ during diestrus (DiE), proestrus (ProE), oestrus (E), and

some males GHRH neurons (shown in supplemental text, Fig. 2, available at www.jneurosci.org as supplemental material), whereas they decreased action potential firing rates in a subset of males GHRH neurons. These bolus effects were transient and action potential firing rates returned to baseline within 8-10 min with a monotonic time course.

The pharmacology of the receptors involved in the effects of $\mathrm{CCh}$ was evaluated. The muscarinic antagonist atropine $10 \mu \mathrm{M}$ antagonized both the stimulatory and the inhibitory effects of CCh $10 \mu \mathrm{M}$ ( $n=7$, in males) (data not shown). Because the cerebral distribution of $\mathrm{M}_{1}$ receptors exhibits sexual dimorphism (Fragkouli et al., 2006), we tested the effects of the $M_{1}$ agonist McN-A343 on GHRH neurons. Like CCh, McN-A343 (10 $\mu \mathrm{M})$ enhanced action potential frequency in all tested GHRH neurons from females (Fig. $3 E$ ), but did not significantly change the firing rates of male GHRH neurons. However, both inhibitory and stimulatory effects of $\mathrm{McN}-\mathrm{A} 343$ were evident in male GHRH neurons (Fig. 3E). To test the hypothesis that other muscarinic receptors might be involved, experiments were performed with an $\mathrm{M}_{1}$ antagonist, pirenzepine, found previously to modulate $\mathrm{GH}$ secretion in rodents (for review, see Giustina and Veldhuis, 1998; Müller et al., 1999). As summarized in Figure 3, $F$ and $G$, pirenzepine $(3 \mu \mathrm{M})$ antagonized the effects of CCh $10 \mu \mathrm{M}$ to enhance GHRH neuronal action potential frequencies [four of four in females (Fig. 3F); nine of 10 in males (Fig. 3G)]. Pirenzepine did not convert inhibitory effects of $\mathrm{CCh}$ in males to stimulatory effects. In 1 of 10 experiments in this series, CCh $10 \mu \mathrm{M}$ lowered the GHRH neuron firing rate, and this was blunted by pirenzepine $3 \mu \mathrm{M}$ (data not shown). Thus, we can conclude that the muscarinic regulation of GHRH neurons is mediated by the $M_{1}$ 

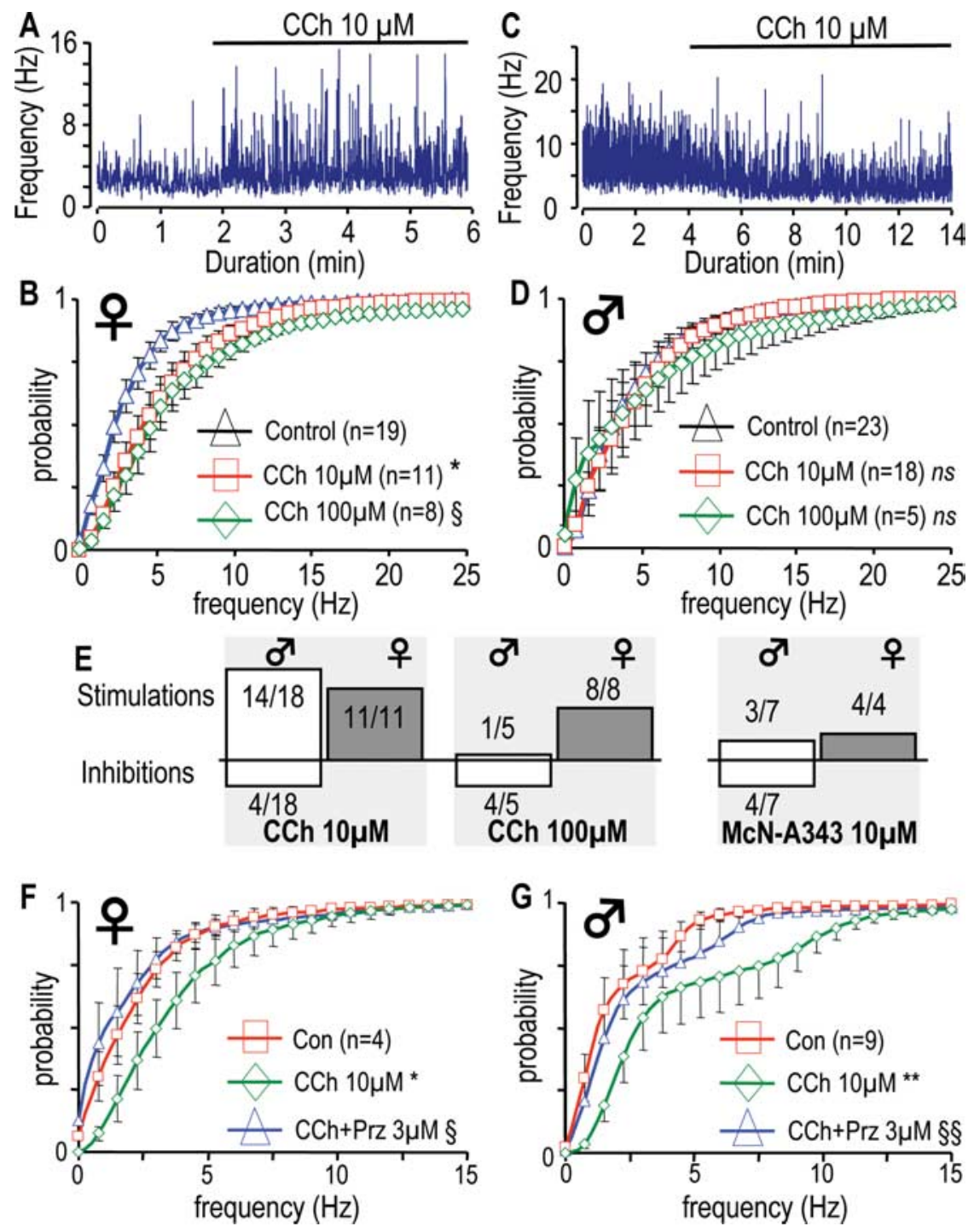

Figure 3. The muscarinic agonist, carbachol, has different effects on the firing rates in male and female GHRH-GFP neurons. $\boldsymbol{A}$, $\boldsymbol{C}$, Effects of $10 \mu \mathrm{M} C \mathrm{C}$ on the instantaneous frequency of the action potentials recorded in a female $(\boldsymbol{A})$ and in a male (C) GHRH-GFP neuron with the loose patch-clamp technique. The presence of $C C h$ is indicated by the solid lines. $B, D$, Cumulated histograms of the mean instantaneous frequency of action potentials recorded in female $(\boldsymbol{B})$ and male $(\boldsymbol{D})$ neurons in the absence or presence of CCh at either $10 \mu \mathrm{m}$ or $100 \mu \mathrm{m}$. ${ }^{*} 0.0005<p<0.05$ versus control in the $0.25-20 \mathrm{~Hz}$ range; ${ }^{\S} 0.0005<p<0.05$ versus control in the $1-13.5 \mathrm{~Hz}$ range, paired Student's $t$ test. $\boldsymbol{E}$, Stimulatory and inhibitory effects of CCh (10 or $100 \mu \mathrm{M})$ or McN-A343 (10 $\mu \mathrm{M})$ observed in male and female GHRH-GFP neurons, are indicated as upward or downward bars. $\boldsymbol{F}, \mathbf{G}$, Same presentation as in $\boldsymbol{B}$ and $D$ except that the effects of $3 \mu \mathrm{m}$ pirenzepine are summarized in experiments in which CCh $10 \mu \mathrm{m}$ had stimulatory effects in female $(\boldsymbol{F})$ and male $(\boldsymbol{G})$ neurons. ${ }^{*} 0.01<p<0.05$ versus control, range $0.25-4.25 \mathrm{~Hz} ;{ }^{* *} 0.001<p<0.05$ versus control, range $0.5-5.5 \mathrm{~Hz} ;{ }^{\S} 0.01<p<0.05$ versus $\mathrm{CCH}$, range $0.75-4.5 \mathrm{~Hz},{ }^{\S \S} 0.001<p<0.05$ versus $\mathrm{CCh}$, range $0.25-4.5 \mathrm{~Hz}$, paired Student's $t$ tests. ns, Not significant.

Table 1. Characteristics of the action potential in GHRH-GFP neurons

\begin{tabular}{|c|c|c|c|c|}
\hline \multirow[b]{2}{*}{ Active properties } & \multicolumn{2}{|l|}{ Control values } & \multicolumn{2}{|c|}{ Plus carbachol (\% over control) } \\
\hline & Males $(n=48)$ & Females $(n=42)$ & Males $(n=5)^{a}$ & Females $(n=5)^{b}$ \\
\hline Threshold & $-42.8 \pm 0.8 \mathrm{mV}$ & $-44.5 \pm 1.1 \mathrm{mV}$ & $+1.6 \pm 4.4$ & $+2.2 \pm 4.3$ \\
\hline Peak & $19.2 \pm 1.5 \mathrm{mV}$ & $16.8 \pm 1.2 \mathrm{mV}$ & $-7.8 \pm 4.9$ & $-2.8 \pm 5.8$ \\
\hline Time to peak & $2.7 \pm 0.3 \mathrm{~ms}$ & $2.7 \pm 0.4 \mathrm{~ms}$ & $+8.6 \pm 8.1$ & $+1.1 \pm 9.3$ \\
\hline Time to $10 \%$ & $1.38 \pm 0.13 \mathrm{~ms}$ & $1.34 \pm 0.14 \mathrm{~ms}$ & $-1.8 \pm 7.1$ & $+1.4 \pm 10.9$ \\
\hline Half-width & $1.3 \pm 0.1 \mathrm{~ms}$ & $1.2 \pm 0.1 \mathrm{~ms}$ & $+4.5 \pm 4.7$ & $+9.7 \pm 7.8$ \\
\hline AHP & $-58.2 \pm 1.1 \mathrm{mV}$ & $-57.9 \pm 1.0 \mathrm{mV}$ & $+2.4 \pm 4.5$ & $+7.5 \pm 4.7$ \\
\hline Time to AHP & $6.5 \pm 0.4 \mathrm{~ms}$ & $6.1 \pm 0.4 \mathrm{~ms}$ & $+6.3 \pm 5.1$ & $+2.9 \pm 6.2$ \\
\hline
\end{tabular}

The number of observations is indicated in parentheses. AHP, Afterhyperpolarization.

${ }^{a} \mathrm{CCh}, 10 \mu \mathrm{m}$.

${ }^{b}$ Pooled data, CCh $10 \mu \mathrm{M}(n=2)$, and $100 \mu \mathrm{M}(n=3)$. receptor in both males and females. It revealed differences in effects between males and females not apparent from spontaneous firing patterns in unstimulated slices.

\section{Action potential and membrane properties of male and female GHRH-GFP neurons}

Action potentials in GHRH-GFP neurons were triggered by transient injections of current and their main properties, summarized in Table 1, were not different between genders. In addition, $\mathrm{CCh}$ (10 or 100 $\mu \mathrm{M})$ did not significantly modify any of these parameters in GHRH-GFP neurons from either males or females (Table 1).

The infrathreshold membrane properties of GHRH-GFP neurons were also examined in the current-clamp mode. The mean resting potential was similar in males and females $(-52.2 \pm 0.6 \mathrm{mV}, n=$ 49 ; and $-52.4 \pm 1.1 \mathrm{mV}, n=29$, respectively). Steady-state current-voltage relationships were established (see Materials and Methods) in the -100 to $-50 \mathrm{mV}$ range, from which mean slope values $(1.80 \pm 0.16$ and $1.85 \pm 0.16 \mathrm{G} \Omega)$ and mean intercept values $(-41.3 \pm 0.3$ and $-41.8 \pm 0.3 \mathrm{mV}$, respectively) did not differ between male $(n=26)$ and female $(n=$ 19) GHRH-GFP neurons. In addition, CCh did not change these parameters when applied alone or in the presence of TTX to reduce spontaneous synaptic activity (Table 2). Altogether, these results suggested that CCh did not act directly on voltage-dependent ion channels of GHRH-GFP neurons, prompting us to investigate the indirect muscarinic regulation of their stimulatory and inhibitory synaptic currents.

Glutamatergic synaptic currents in male and female GHRH-GFP neurons

Fast inward synaptic currents were recorded at $-70 \mathrm{mV}$ under steady-state conditions (Fig. 4A) and behaved as cationic currents (our unpublished observation). They will be referred to as spontaneous EPSCs (sEPSCs). The amplitude and the instantaneous frequency of the sEPSCs fluctuated during recordings in GHRHGFP neurons, and the distributions of these parameters are shown in Figure $4 B$. The amplitude distributions exhibited gender differences (Fig. 4B, top), with sEPSCs being significantly higher in the 9-90 pA range, in female GHRH-GFP neurons $(0.0005<p<0.05$, one-way ANOVA; $p<0.0001$, KS test). In contrast, the instantaneous frequency distributions were super imposable in males and females (Fig. $4 B$, bottom), with $\sim 80 \%$ 
higher than $1 \mathrm{~Hz}$. The kinetics of the sEPSCs were also identical in the two groups (our unpublished observation). Thus, although these are depolarizing currents with higher amplitude in females, they do not give rise to any difference in spontaneous action potential firing between males and females.

The behavior of the presynaptic nerve terminals was examined in the presence of tetrodotoxin (TTX), which blocks action potential propagation, but does not modify spontaneous release at nerve terminals, evident as miniature currents (mEPSCs). In the experiment shown in Figure $4 C$, where a GHRH-GFP neuron had been superfused with TTX $(0.5 \mu \mathrm{M})$, the addition of CNQX $(20 \mu \mathrm{M})$, an antagonist at AMPA and kainate, glutamatergic ionotropic receptors, totally and selectively suppressed the mEPSCs (five experiments). These were further characterized at $-70 \mathrm{mV}$. The perfusion of TTX consistently reduced current amplitudes in both males ( $0.001<p<0.05$ vs control; range, 9.5-29 pA; paired Student's $t$ test) and females $(0.001<p<0.05$ vs control; range, 8.5-28 pA; paired Student's $t$ test). As a result, $70 \%$ of the mEPSCs were smaller than $14 \mathrm{pA}$ and their distributions were indistinguishable in male and female GHRH neurons (Fig. 4D, top). TTX also decreased the frequencies of the glutamatergic currents in both males $(0.0005<$ $p<0.05$ vs control; range, $0.15-80 \mathrm{~Hz}$; paired Student's $t$ test) and females (0.0001 $<p<0.05$ vs control; range, $0.16-80 \mathrm{~Hz}$; paired Student's $t$ test). Thus, only $\sim 55 \%$ of mEPSC frequencies were larger than $1 \mathrm{~Hz}$ and their distributions did not exhibit gender differences (Fig. $4 D$, bottom). We concluded that the activity of the afferent glutamatergic system, but not of the glutamatergic synapse itself, was responsible for the differences in the amplitude of the spontaneous glutamatergic currents between male and female GHRH neurons.

\section{Carbachol stimulates glutamatergic currents in male and female GHRH-GFP neurons}

An increase in the afferent glutamatergic synaptic inputs could readily account for the stimulatory effects of CCh on action potential firing. Thus, the effects of CCh superfusion on spontaneous glutamatergic sEPSCs of GHRH-GFP neurons were recorded at $-70 \mathrm{mV}$. Recordings of glutamatergic activity in the presence and absence of $100 \mu \mathrm{M}$ CCh (Fig. 5A) suggested that this muscarinic agonist predominantly modulated frequencies. On average, it was found that CCh increased the instantaneous frequencies of glutamatergic sEPSCs in both male (Fig. $5 B$ ) and female (Fig. $5 C$ ) GHRH-GFP neurons. This effect was significant at 10 and $100 \mu \mathrm{M}$ in each experiment (for detailed values, see Fig. 5 legend). CCh (1$100 \mu \mathrm{M}$ ) did not modify the amplitude and the kinetics of the sEPSCs in these experiments (data not shown).

In the next experiments, the activity of the glutamatergic syn-
Table 2. Effect of carbachol on the properties of GHRH-GFP neurons

\begin{tabular}{|c|c|c|c|c|}
\hline \multirow{2}{*}{$\begin{array}{l}\text { Infrathreshold properties } \\
(\% \text { over control })^{a}\end{array}$} & \multicolumn{2}{|l|}{ Males } & \multicolumn{2}{|l|}{ Females } \\
\hline & Slope & Intercept & Slope & Intercept \\
\hline Carbachol $10 \mu \mathrm{M}$ & $-1.4 \pm 3.4(5)$ & $-4.7 \pm 3.3(5)$ & $-6.0 \pm 11.3(3)$ & $+5.0 \pm 8.4(3)$ \\
\hline Carbachol $100 \mu \mathrm{M}$ & & & $-4.3 \pm 6.4(5)$ & $-5.4 \pm 8.9(5)$ \\
\hline TTX $500 \mathrm{~nm}$ & $-5.6 \pm 3.6(7)$ & $-4.4 \pm 3.8(7)$ & $-1.1 \pm 4.7(6)$ & $-0.7 \pm 6.8(6)$ \\
\hline TTX plus carbachol $10 \mu \mathrm{M}$ & $-4.1 \pm 5.5(6)$ & $-1.9 \pm 4.4(6)$ & $-0.9 \pm 9.4(6)$ & $-2.6 \pm 12.4(6)$ \\
\hline TTX plus carbachol $100 \mu \mathrm{M}$ & $-8.7 \pm 6.2(5)$ & $-2.2 \pm 4.5(5)$ & & \\
\hline
\end{tabular}

The number of observations is indicated in parentheses.
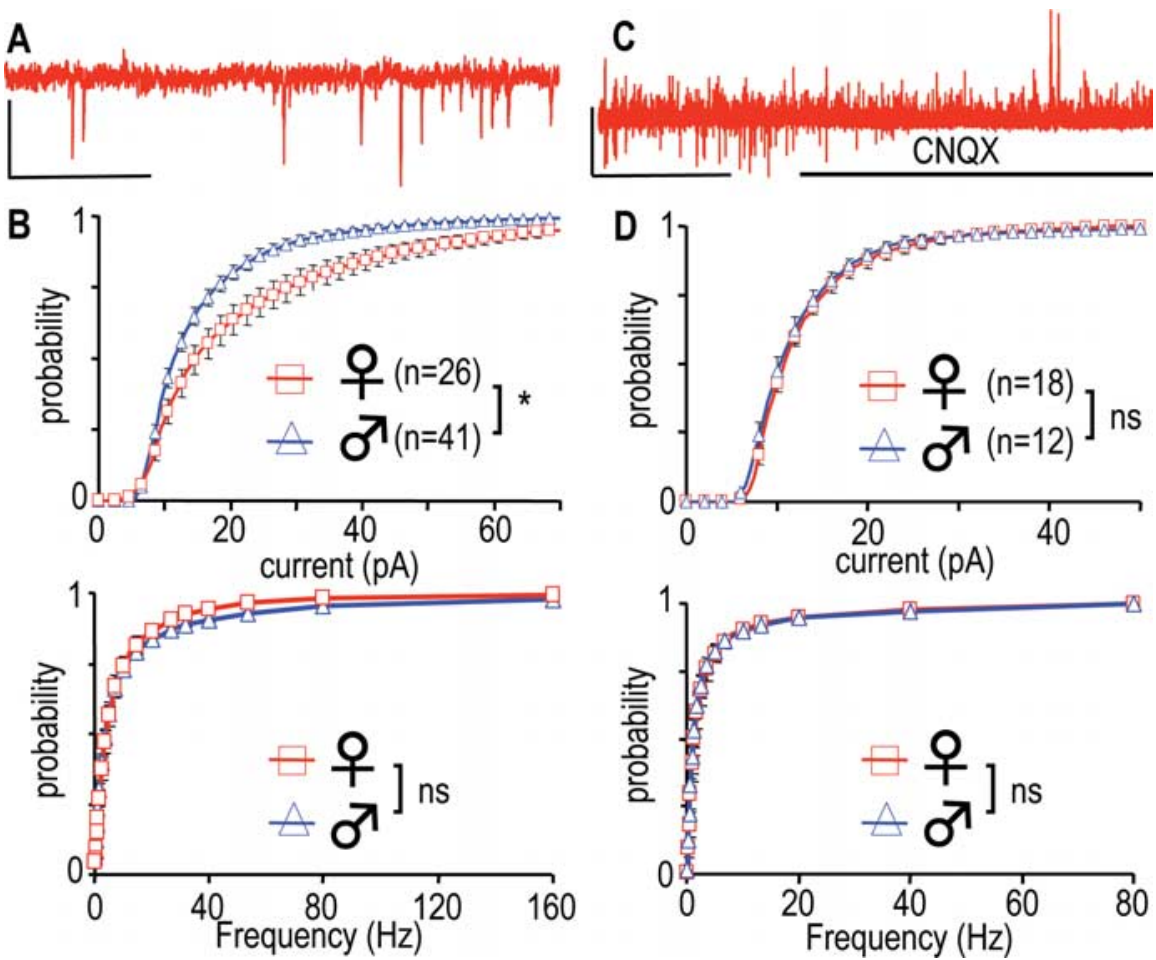

Figure 4. Glutamatergic afferent control of GHRH-GFP neurons. $\boldsymbol{A}$, Trace recorded in a male GHRH-GFP neuron at $-70 \mathrm{mV}$. $\boldsymbol{B}$ Cumulated histograms of the mean distributions of the amplitudes (top) and the instantaneous frequencies (bottom) of sEPSCs in

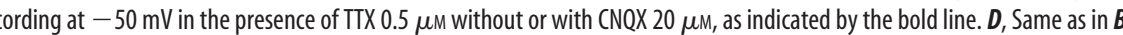
except that the currents were recorded in the presence of $0.5 \mu \mathrm{m}$ TTX in male $(n=18)$ and female $(n=12)$ GHRH-GFP neurons. Calibrations: $A, 30$ pA, 0.5 s; C, 60 pA, 50 s. ns, Not significant.

apses was isolated with TTX, and the effects of CCh were examined. As illustrated in Fig. 6A, CCh (10 and $100 \mu \mathrm{M})$ enhanced glutamatergic transmission in male GHRH neurons. The results of similar experiments were summarized in Figure 6, $B$ and $C$. In the presence of TTX, CCh did not modify the amplitude distributions of the glutamatergic mEPSCs in either male or female GHRH-GFP neurons (Fig. $6 B, C$, top), but strongly enhanced their frequencies (bottom) $(p<0.05)$. Thus, CCh enhanced the glutamatergic transmission at a presynaptic site, in both male and female GHRH-GFP neurons. This likely accounted for the stimulatory effect of the muscarinic agonist on the electrical activity of GHRH-GFP neurons in both genders. A mechanism for the inhibitory effect of CCh on action potential firing of male GHRHGFP neurons was then investigated.

\section{GABAergic synaptic currents in male and female GHRH-GFP neurons}

A second type of synaptic currents was routinely recorded at -30 $\mathrm{mV}$ under steady-state conditions (Fig. 7A), and these were 
A Control

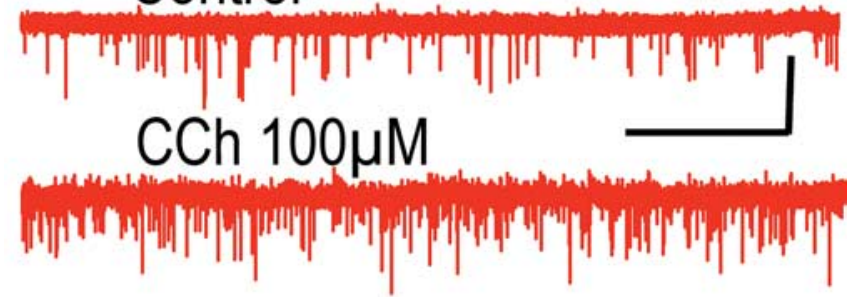
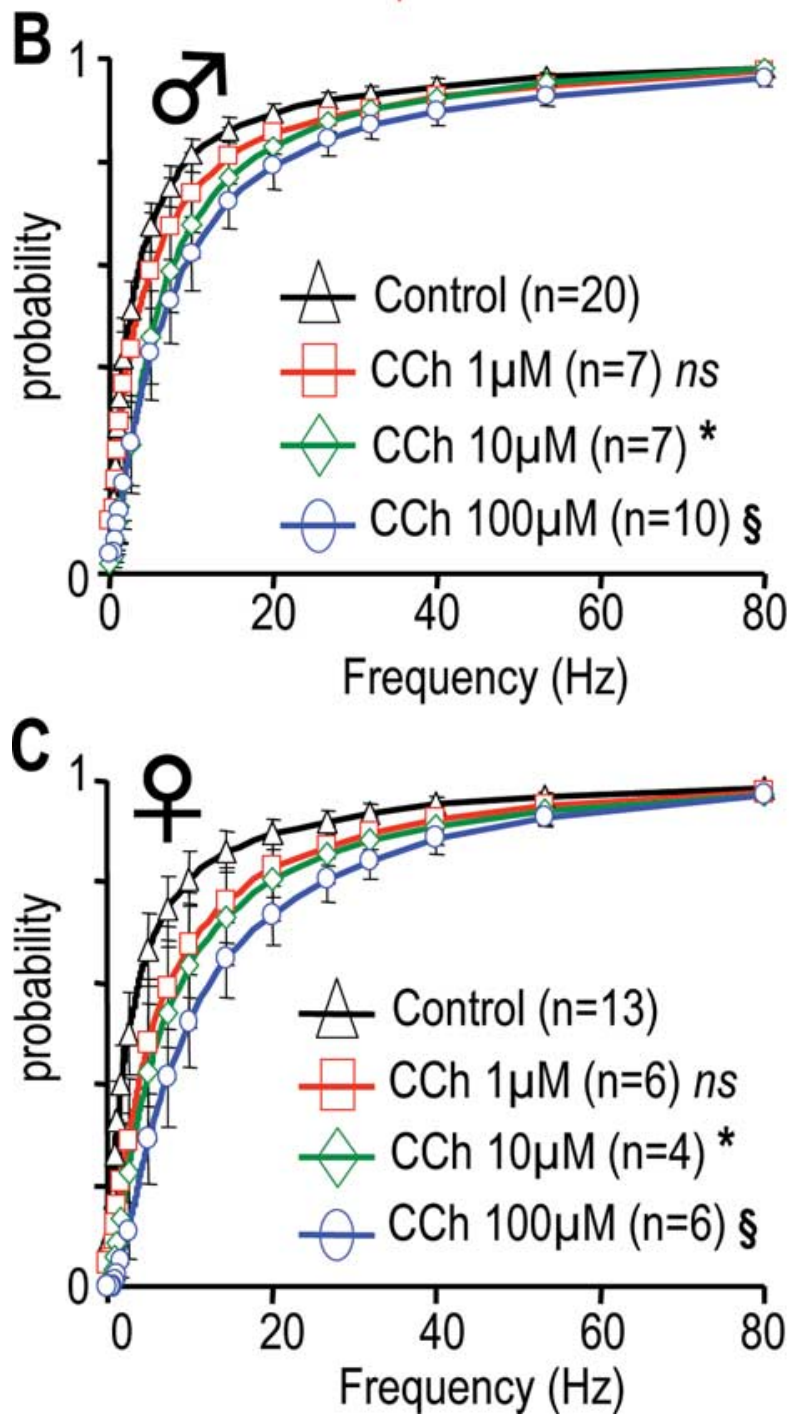

Figure 5. CCh enhances glutamatergic inputs at GHRH-GFP neurons in males and females. $\boldsymbol{A}$, Traces recorded at $-70 \mathrm{mV}$ in a male neuron, in the absence or presence of $C \mathrm{Ch}$. Calibration: 40 pA, 20 s. $B, C$, Cumulated distributions of the instantaneous frequencies of glutamatergic currents recorded in male $(\boldsymbol{B})$ and female $(\boldsymbol{C})$ neurons. Currents were recorded in the absence $(\diamond)$ or presence of $C(h$ at $1(\square), 10(\diamond)$, or $100 \mu \mathrm{m}(\bigcirc)$. Differences with control distributions were indicated in $\boldsymbol{B}$ as ${ }^{*} 0.005<p<0.05$ in the $0.69-80 \mathrm{~Hz}$ range, ${ }^{\S} 0.001<p<0.05,0.61-80$ $\mathrm{Hz}$ range, and in $\mathrm{Cas}{ }^{*} 0.001<p<0.05,0.5-5.7 \mathrm{~Hz}$ range, ${ }^{\S} 0.005<p<0.05,1.14-80 \mathrm{~Hz}$ range (paired Student's $t$ tests). ns, Not significant.

found to be outward chloride currents (our unpublished observation). They will be referred to as spontaneous IPSCs (sIPSCs). Their amplitude and instantaneous frequencies fluctuated during recordings, and the distributions of these parameters are shown in Figure $7 B$. On average, neither the sIPSC amplitude distributions, with $\sim 70 \%$ of the inputs in the $0-20$ pA range (Fig. $7 B$, top), nor their kinetics (data not shown) were different in male and female GHRH-GFP neurons. Around 70\% of the instantaneous frequencies were larger than $2.5 \mathrm{~Hz}$ and their distributions (Fig. $7 B$, bottom) did not differ between the genders. These currents were also examined in the presence of TTX. In the experiment shown in Fig. $7 C$, where a GHRH-GFP neuron had been superfused with TTX $(0.5 \mu \mathrm{M})$, the addition of GABAzine ( 3 $\mu \mathrm{M})$, a competitive antagonist at $\mathrm{GABA}_{\mathrm{A}}$ receptors, totally suppressed the outward miniature currents (mIPSCs) in a selective manner (repeated in five experiments). The mIPSCs were studied further at $-30 \mathrm{mV}$ (Fig. 7D). Perfusion of TTX on GHRH-GFP neurons reduced mIPSC amplitudes in the 9.5-85.5 pA range in males $(0.0001<p<0.05$, paired Student's $t$ test $)$ and in the $9-81$ pA range in females $(0.01<p<0.05$, paired Student's $t$ test $)$. In addition, it decreased their frequencies in the $0.25-80 \mathrm{~Hz}$ range in males $(0.0001<p<0.05$, paired Student's $t$ test $)$ and in the $0.8-40 \mathrm{~Hz}$ range in females $(0.001<p<0.05$, paired Student's $t$ test). As a result, most mIPSCs $(\sim 70 \%)$ were smaller than $14 \mathrm{pA}$ and similarly distributed in males and females (Fig. $7 D$, top), and their frequency distributions were identical in both genders (Fig. $7 D$, bottom), suggesting that GABAergic synapses on GHRHGFP neurons had a similar activity in both sexes.

\section{Carbachol differentially regulates GABAergic synaptic currents in male and female GHRH-GFP neurons}

We then investigated a potential modulatory effect of CCh on this GABAergic input to GHRH-GFP neurons. The recordings shown in Figure $8 \mathrm{~A}$ were from a male GHRH-GFP neuron where the effect of CCh was examined at $-30 \mathrm{mV}$. CCh enhanced the GABAergic input, without modifying the kinetics of the GABAergic currents. On average, in similar experiments, $100 \mu \mathrm{M}$ CCh strongly increased their instantaneous frequencies (Fig. $8 \mathrm{~B}$ ) in male GHRH-GFP neurons without significantly changing the amplitude of the sIPSCs (data not shown). In addition, CCh at 10 $\mu \mathrm{M}$, but not at $1 \mu \mathrm{M}$, also tended to increase the frequencies distribution in four of six experiments. Because CCh did not change the kinetics of the sIPSCs in these experiments (data not shown), the net effect of the muscarinic agonist was to increase GABAergic neurotransmission. The effects of CCh (1-100 $\mu \mathrm{M})$ on GABAergic transmission in female GHRH neurons are summarized in Figure 8C. Neither the instantaneous frequency (Fig. $8 C$ ), nor the amplitude and the kinetics (data not shown) of the spontaneous GABAergic currents were affected. Thus, the muscarinic regulation of GABAergic neurotransmission was only evident in male GHRH-GFP neurons, and this could explain why the inhibitory effect of this agonist was only observed in male GHRH-GFP neurons.

The activity of the GABAergic synapses was isolated with TTX, and the effects of CCh were examined in male GHRH-GFP neurons. The traces in Figure $8 D$ were recorded successively at -30 $\mathrm{mV}$ in the presence of TTX alone and in the presence of TTX plus CCh at 10 and $100 \mu \mathrm{M}$. In this set of experiments (Fig. 8E), TTX strongly decreased frequencies (bottom) and slightly reduced amplitudes (top) of the GABAergic currents. Importantly, in the presence of TTX, CCh $(10$ or $100 \mu \mathrm{M})$ did not modify the distributions of the amplitudes (Fig. $8 \mathrm{E}$, top) or of the frequencies (bottom) of the mIPSCs. Similar results were found in female GHRH-GFP neurons (data not shown). Therefore, CCh enhanced the GABAergic transmission at a distant site within the afferent system, in male, but not in female GHRH-GFP neurons. We believe that this accounted for the overall inhibitory effects of muscarinic agonists on some male GHRH-GFP neurons. 


\section{Discussion}

Our study described GHRH neurons and their regulation by afferent systems. There were no obvious direct spontaneous differences in firing rates of identified GHRH neurons in males or females, and teasing out gender differences required more complex analyses of both intrinsic and extrinsic properties of this neuropeptide system. In particular, muscarinic activation via $M_{1}$ receptors revealed a gender difference in the activity of the afferent systems, and suggested that the organization of GHRH neuronal activity involved at least a dual level of afferent controls, whose balance differed between males and females.

\section{Intrinsic properties of \\ GHRH-GFP neurons}

The pulsatility of GHRH secretion, occurring from the nerve terminals in the median eminence is controlled, in most part, by the electrical activity of GHRH cell bodies in the arcuate nucleus. Electrical stimulation of the arcuate nucleus is more effective in eliciting GH release than stimulation of the median eminence, and is dependent on long bursts of activation (Dickson et al., 1993). A central question in this system is the origin of GH pulsatility, and whether this is intrinsic to GHRH neurons (Giustina and Veldhuis, 1998; Wagner et al., 1998; Müller et al., 1999; Farhy et al., 2001, 2002; Veldhuis et al., 2005). GHRH neurons did not behave like pacemakers cells because they did not exhibit regular spontaneous rhythmic activity, nor was the action potential firing rate of GHRH neurons clustered into short term bursting patterns. Thus, although ionic channels of GHRH neurons likely contribute to the overall episodic pattern of GHRH secretion, their properties are not the primary mechanisms that trigger or shape the secretory pulses.

Rather, we believe our results showed that the interactions of afferent inputs to GHRH neurons must be involved in the generation of GHRH (and hence GH) pulses. The fast neurotransmitters GABA and glutamate were implicated previously in controlling GH secretion (Giustina and Veldhuis, 1998; Gonzalez et al., 1999; Müller et al., 1999; Pinilla et al., 1999), and we can now confirm that they regulate GHRH neurons directly, in a monosynaptic manner. Furthermore, disabling action potential propagation with TTX blunted of the effects of these neurotransmitters on GHRH neurons in vitro. Afferent GABA and glutamatergic cell bodies are present either in the arcuate nucleus (Belousov and van den Pol, 1997; Liu et al., 1999), or in nearby afferent structures (Sternson et al., 2005) and were active in our acute slice preparations. In the presence of TTX, GABAergic inputs were two to three times more frequent than glutamatergic currents, but this difference was smaller under conditions of spontaneous activity, suggesting that under these conditions the glutamatergic system was more activate than the GABAergic system.

\section{Dual-level control of GHRH-GFP neurons}

Our data also demonstrated that GABAergic and glutamatergic afferent systems to the GHRH neurons may participate in the muscarinic regulation of GHRH release and, hence, $\mathrm{GH}$ secretion (Magnan et al., 1993; Giustina and Veldhuis, 1998; Rigamonti et al., 1998; Müller et al., 1999). GABAergic and glutamatergic neurons are known to control the activity of other (i.e., non-GHRH) neurons within the arcuate nucleus (Belousov and van den Pol, 1997; Liu et al., 1999; Horvath and Diano, 2004; Acuna-Goycolea et al., 2005; Sternson et al., 2005). How then, are these afferent neurotransmitter systems organized within the arcuate nucleus to achieve selective but coordinated secretions of different neuropeptides?

Perhaps the simplest possibility is a "vertical" type of organization, where each neuropeptidergic system has its own afferent system. Recent studies are demonstrating that monosynaptic afferent inputs to NPY neurons and pro-opiomelanocortin neurons originate from distinct structures (Sternson et al., 2005). Modulations of this afferent stratum is repeatedly found in the arcuate nucleus, as well as in the lateral hypothalamus (for review, see Horvath and Diano, 2004). In line with this, our results suggested a cholinergic effect at a presynaptic site to strengthen 

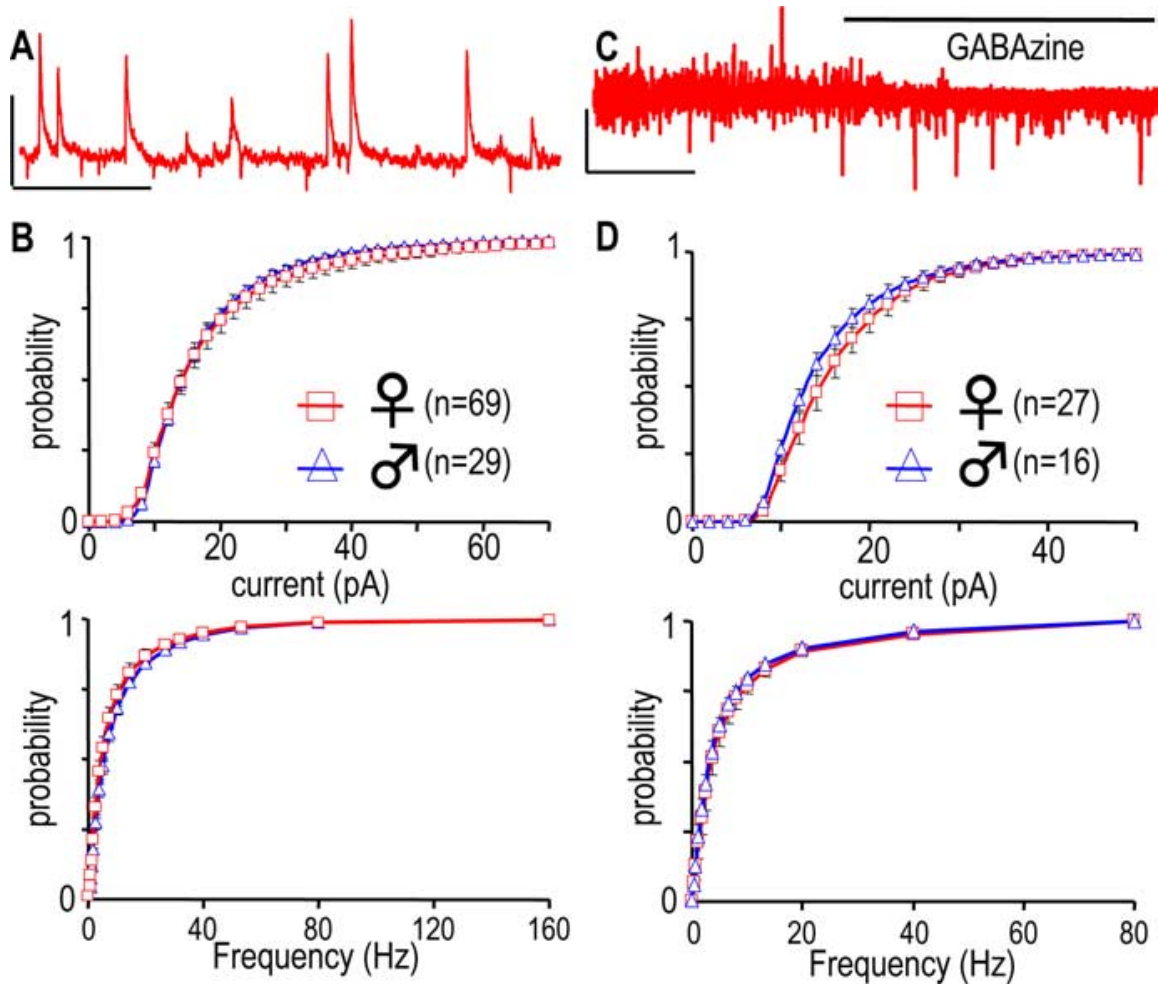

Figure 7. GABAergic afferent control of GHRH-GFP neurons. $\boldsymbol{A}$, Recording from a male GHRH-GFP neuron held at $-30 \mathrm{mV}$. $\boldsymbol{B}$, Cumulated histograms of the mean distributions of the amplitudes (top) and the instantaneous frequencies (bottom) of sIPSCs recorded in male and female GHRH-GFP neurons at $-30 \mathrm{mV}$. C, Recording at $-50 \mathrm{mV}$, in the presence of $0.5 \mu \mathrm{m}$ TTX without or with $3 \mu \mathrm{m}$ GABAzine, as indicated by the bold line. $D$, Same as in $B$ except that the currents were recorded in the presence of $0.5 \mu \mathrm{M}$ TTX in males and females GHRH-GFP neurons. Calibration: $\boldsymbol{A}, 60 \mathrm{pA}, 0.5 \mathrm{~s} ; \boldsymbol{C}, 40 \mathrm{pA}, 50 \mathrm{~s}$.

glutamatergic transmission to GHRH neurons. Such a specific vertical hierarchy of afferents meets the needs of specific regulation of individual neuropeptide systems within the arcuate nucleus. A neuromodulator such as acetylcholine can orchestrate several peptidergic functions within and beyond the arcuate nucleus. For example, it can regulate GHRH (Magnan et al., 1993; Rigamonti et al., 1998), tuberoinfundibular dopaminergic neurons (Shieh and Pan, 1995; Chu et al., 2001), orexin neurons (lateral hypothalamus) (Yamanaka et al., 2003; Sakurai et al., 2005), CRH neurons (paraventricular area) (Tizabi and Calogero, 1992; Ohmori et al., 1995), and possibly SRIH neurons (periventricular area) (Giustina and Veldhuis, 1998; Müller et al., 1999). Furthermore, monosynaptic inputs to neuropeptidecontaining neurons can undergo functional remodelling (Horvath and Diano, 2004; Sternson et al., 2005), which implies the existence of an upper-level stratum of afferent control.

This complexity might require a more distant afferent control system, capable of generalized alterations of more than one peptide system. In this context, it is interesting that our results produced evidence for a muscarinic regulation of GABAergic neurotransmission at a location distant from GHRH neurons, and abrogated by TTX treatment. This could represent a more distant stratum of afferent arborization, and may not be specific for GHRH neurons, which were the only ones being recorded from in our study. In this dual model, we suggest that the muscarinic regulation of glutamatergic inputs might selectively adjust GHRH neurons locally, whereas a muscarinic regulations of GABAergic neurotransmission at a more distant site might orchestrate a more general neuropeptide response, for instance, the preparation and/or maintenance of arousal (Sakurai, 2005). It could also provide a means for the more long term coordination of other conditional inputs (e.g., ingestive, metabolic, and growth responses) to which several types of arcuate neuropeptide neurons respond, not only GHRH neurons (Giustina and Veldhuis, 1998; Müller et al., 1999).

\section{Gender differences in the control of GHRH-GFP neurons}

Physiological GH secretory patterns are markedly sexually dimorphic. We concentrated on identifying electrophysiological mechanisms that might underlie these gender differences that appear in GHRH secretion, GHRH expression, SRIHergic input, and steroid receptor expression (Giustina and Veldhuis, 1998; Müller et al., 1999; Chowen et al., 2004). However, the intrinsic properties of GHRH neurons were remarkably similar in males and in females throughout the phases of the oestrus cycle. This did not rule out other sexual dimorphic features, but seemed to rule out the possibility that such differences were simply reflected in differences in electrical activity of GHRH neurons. Note that action potential frequency is not modified in $50 \%$ of arcuate nucleus neurons after estradiol treatment of ovariectomized rats (Parducz et al., 2002), and our data suggested that GHRH neurons might belong to this population.

To our surprise, the gender differences in GHRH neuronal activity were complex, both in afferent glutamatergic currents, and in the muscarinic regulation of the GABAergic neurotransmission. Because they were related to a long-distance control of GHRH neurons, it is tedious to investigate the precise locations of these sexual differences. Additional studies, using retrograde markers of afferent systems of GHRH neurons (DeFalco et al., 2001), might help in locating the sites of this differential afferent regulation. Interestingly, in the arcuate nucleus of ovariectomized rats, estradiol downregulated the number of GABAergic synapses of hypophysiotropic neurons (Parducz et al., 1993, 2003) and increased the number of excitatory synapses (Parducz et al., 2002). This fits with our findings of higher glutamatergic currents in females, and of a muscarinic stimulation of GABAergic neurotransmission only seen in males.

It is curious that the higher glutamatergic currents in females did not give rise to significant gender differences in the spontaneous action potential firing rate. We speculate that glutamatergic currents are already large enough in males to elicit subthreshold depolarizations of GHRH neurons, and that larger currents, as seen in females, might not increase action potential firing further. In contrast, a marked sexual dimorphism in action potential frequency was observed with carbachol, which only enhanced firing in females, but exerted either inhibitory or stimulatory effects in males. These effects were mimicked by McN-A343, an $\mathrm{M}_{1}$ agonist, and antagonized by pirenzepine, an $\mathrm{M}_{1}$ antagonist, suggesting that $\mathrm{M}_{1}$ muscarinic receptor activation mediated these responses. We note that the cerebral distribution of $\mathrm{M}_{1}$ receptors is different in males and females (Fragkouli et al., 2006) and that expression of cholinergic markers is sexually dimorphic (Rhodes 
and Rubin, 1999). However, the consequences of $M_{1}$ receptor activation might also differ if the target neurons exhibited gender differences. Because there is no evidence that cholinergic neurons control the sexual dimorphism of GHRH secretion per se (Giustina and Veldhuis, 1998; Müller et al., 1999), we believe it more likely that muscarinic activation unveiled gender differences in the organization of the afferent inputs.

This is the first detailed analysis of the properties and control of identified GHRH neurons in males and females. Our results suggested that the primary control of pulsatility and gender differences in activity lie somewhat distant to GHRH neurons, with at least two levels of afferent organization and neurotransmitter interaction. The more distant inputs, abrogated in our experiments by TTX, are involved both in the sexual dimorphism of glutamatergic inputs to GHRH neurons, as well as in the sexual dimorphism of the muscarinic control of the afferent GABAergic neurotransmission on GHRH neurons. Additional studies will be required to establish the location and roles of these more long-distance afferents in the coordination of specific hypothalamic neuropeptide secretion.

\section{References}

Acuna-Goycolea C, Tamamaki N, Yanagawa Y, Obata K, van den Pol AN (2005) Mechanisms of neuropeptide $\mathrm{Y}$, peptide $\mathrm{YY}$, and pancreatic polypeptide inhibition of identified green fluorescent protein-expressing GABA neurons in the hypothalamic neuroendocrine arcuate nucleus. J Neurosci 25:7406-7419.

Alba M, Salvatori R (2004) A mouse with targeted ablation of the growth hormonereleasing hormone gene: a new model of isolated growth hormone deficiency. Endocrinology 145:4134-4143.

Balthasar N, Méry PF, Magoulas CB, Mathers KE, Martin A, Mollard P, Robinson IC (2003) Growth hormone-releasing hormone (GHRH) neurons in GHRH-enhanced green fluorescent protein transgenic mice: a ventral hypothalamic network. Endocrinology 144:2728-2740.

Belousov AB, van den Pol AN (1997) Local synaptic release of glutamate from neurons in the rat hypothalamic arcuate nucleus. J Physiol (Lond) 499:747-761.

Chowen JA, Frago LM, Argente J (2004) The regulation of GH secretion by sex steroids. Eur J Endocrinol 151 [Suppl 3]:U95-U100.

Chu YC, Tsou MY, Pan JT (2001) Prostaglandins may participate in opioidergic and cholinergic control of the diurnal changes of tuberoinfundibular dopaminergic neuronal activity and serum prolactin level in ovariectomized, estrogen-treated rats. Brain Res Bull 56:61-65.

DeFalco J, Tomishima M, Liu H, Zhao C, Cai X, Marth JD, Enquist L, Friedman JM (2001) Virus-assisted mapping of neural inputs to a feeding center in the hypothalamus. Science 291:2608-2613.

Dickson SL, Leng G, Robinson IC (1993) Growth hormone release evoked by electrical stimulation of the arcuate nucleus in anesthetized male rats. Brain Res 623:95-100.

Dimaraki EV, Jaffe CA, Demott-Friberg R, Russell-Aulet M, Bowers CY, Marbach P, Barkan AL (2001) Generation of growth hormone pulsatility in women: evidence against somatostatin withdrawal as pulse initiator. Am J Physiol Endocrinol Metab 280:E489-E495.

Dimaraki EV, Jaffe CA, Bowers CY, Marbach P, Barkan AL (2003) Pulsatile and nocturnal growth hormone secretions in men do not require periodic declines of somatostatin. Am J Physiol Endocrinol Metab 285:E163-E170.

Farhy LS, Straume M, Johnson ML, Kovatchev B, Veldhuis JD (2001) A construct of interactive feedback control of the GH axis in the male. Am J Physiol Regul Integr Comp Physiol 281:R38-R51.

Farhy LS, Straume M, Johnson ML, Kovatchev B, Veldhuis JD (2002) Unequal autonegative feedback by $\mathrm{GH}$ models the sexual dimorphism in $\mathrm{GH}$ secretory dynamics. Am J Physiol Regul Integr Comp Physiol 282:R753-R764.

Fragkouli A, Stamatakis A, Zographos E, Pachnis V, Stylianopoulou F (2006) Sexually dimorphic effects of the Lhx7 null mutation on forebrain cholinergic function. Neuroscience 137:1153-1164.

Gaylinn BD, Dealmeida VI, Lyons Jr CE, Wu KC, Mayo KE, Thorner MO (1999) The mutant growth hormone-releasing hormone (GHRH) receptor of the little mouse does not bind GHRH. Endocrinology 140:5066-5074.

Giustina A, Veldhuis JD (1998) Pathophysiology of the neuroregulation of growth hormone secretion in experimental animals and the human. Endocr Rev 19:717-797. 
Gonzalez LC, Pinilla L, Tena-Sempere M, Aguilar E (1999) Regulation of growth hormone secretion by alpha-amino-3-hydroxy-5methylisoxazole-4-propionic acid receptors in infantile, prepubertal, and adult male rats. Endocrinology 140:1279-1284.

Horvath TL, Diano S (2004) The floating blueprint of hypothalamic feeding circuits. Nat Rev Neurosci 5:662-667.

Jaffe CA, Ocampo-Lim B, Guo W, Krueger K, Sugahara I, DeMott-Friberg R, Bermann M, Barkan AL (1998) Regulatory mechanisms of growth hormone secretion are sexually dimorphic. J Clin Invest 102:153-164.

Jaffe CA, Turgeon DK, Lown K, Demott-Friberg R, Watkins PB (2002) Growth hormone secretion pattern is an independent regulator of growth hormone actions in humans. Am J Physiol Endocrinol Metab 283:E1008-E1015.

Kreienkamp HJ, Akgun E, Baumeister H, Meyerhof W, Richter D (1999) Somatostatin receptor subtype 1 modulates basal inhibition of growth hormone release in somatotrophs. FEBS Lett 462:464-466.

Le Tissier PR, Carmignac DF, Lilley S, Sesay AK, Phelps CJ, Houston P, Mathers K, Magoulas C, Ogden D, Robinson IC (2005) Hypothalamic growth hormone-releasing hormone (GHRH) deficiency: targeted ablation of GHRH neurons in mice using a viral ion channel transgene. Mol Endocrinol 19:1251-1262.

Liu QS, Patrylo PR, Gao XB, van den Pol AN (1999) Kainate acts at presynaptic receptors to increase GABA release from hypothalamic neurons. J Neurophysiol 82:1059-1062.

Low MJ, Otero-Corchon V, Parlow AF, Ramirez JL, Kumar U, Patel YC, Rubinstein M (2001) Somatostatin is required for masculinization of growth hormone-regulated hepatic gene expression but not of somatic growth. J Clin Invest 107:1571-1580.

MacGregor DJ, Leng G (2005) Modeling the hypothalamic control of growth hormone secretion. J Neuroendocrinol 17:788-803.

Magnan E, Cataldi M, Guillaume V, Mazzocchi L, Dutour A, Conte-Devolx B, Giraud P, Oliver C (1993) Neostigmine stimulates growth hormonereleasing hormone release into hypophysial portal blood of conscious sheep. Endocrinology 132:1247-1251.

Müller EE, Locatelli V, Cocchi D (1999) Neuroendocrine control of growth hormone secretion. Physiol Rev 79:511-607.

Neher E (1992) Correction for liquid junction potentials in patch clamp experiments. Methods Enzymol 207:123-131.

Ohmori N, Itoi K, Tozawa F, Sakai Y, Sakai K, Horiba N, Demura H, Suda T (1995) Effect of acetylcholine on corticotropin-releasing factor gene expression in the hypothalamic paraventricular nucleus of conscious rats. Endocrinology 136:4858-4863.

Parducz A, Perez J, Garcia-Segura LM (1993) Estradiol induces plasticity of gabaergic synapses in the hypothalamus. Neuroscience 53:395-401.

Parducz A, Hoyk Z, Kis Z, Garcia-Segura LM (2002) Hormonal enhance- ment of neuronal firing is linked to structural remodelling of excitatory and inhibitory synapses. Eur J Neurosci 16:665-670.

Parducz A, Zsarnovszky A, Naftolin F, Horvath TL (2003) Estradiol affects axo-somatic contacts of neuroendocrine cells in the arcuate nucleus of adult rats. Neuroscience 117:791-794.

Pinilla L, Gonzalez L, Tena-Sempere M, Dieguez C, Aguilar E (1999) Gonadal and age-related influences on NMDA-induced growth hormone secretion in male rats. Neuroendocrinology 69:11-19.

Rhodes ME, Rubin RT (1999) Functional sex differences ("sexual diergism") of central nervous system cholinergic systems, vasopressin, and hypothalamic-pituitary-adrenal axis activity in mammals: a selective review. Brain Res Brain Res Rev 30:135-152.

Rigamonti AE, Marazzi N, Cella SG, Cattaneo L, Muller EE (1998) Growth hormone responses to growth hormone-releasing hormone and hexarelin in fed and fasted dogs: effect of somatostatin infusion or pretreatment with pirenzepine. J Endocrinol 156:341-348.

Sakurai T (2005) Roles of orexin/hypocretin in regulation of sleep/wakefulness and energy homeostasis. Sleep Med Rev 9:231-241.

Sakurai T, Nagata R, Yamanaka A, Kawamura H, Tsujino N, Muraki Y, Kageyama H, Kunita S, Takahashi S, Goto K, Koyama Y, Shioda S, Yanagisawa M (2005) Input of orexin/hypocretin neurons revealed by a genetically encoded tracer in mice. Neuron 46:297-308.

Shieh KR, Pan JT (1995) An endogenous cholinergic rhythm may be involved in the circadian changes of tuberoinfundibular dopaminergic neuron activity in ovariectomized rats treated with or without estrogen. Endocrinology 136:2383-2388.

Sternson SM, Shepherd GM, Friedman JM (2005) Topographic mapping of $\mathrm{VMH} \rightarrow$ arcuate nucleus microcircuits and their reorganization by fasting. Nat Neurosci 8:1356-1363.

Tizabi Y, Calogero AE (1992) Effect of various neurotransmitters and neuropeptides on the release of corticotropin-releasing hormone from the rat cortex in vitro. Synapse 10:341-348.

Veldhuis JD, Farhy L, Weltman AL, Kuipers J, Weltman J, Wideman L (2005) Gender modulates sequential suppression and recovery of pulsatile growth hormone secretion by physiological feedback signals in young adults. J Clin Endocrinol Metab 90:2874-2881.

Wagner C, Caplan SR, Tannenbaum GS (1998) Genesis of the ultradian rhythm of GH secretion: a new model unifying experimental observations in rats. Am J Physiol Endocrinol Metab 275:E1046-E1054.

Yamanaka A, Muraki Y, Tsujino N, Goto K, Sakurai T (2003) Regulation of orexin neurons by the monoaminergic and cholinergic systems. Biochem Biophys Res Commun 303:120-129.

Zheng H, Bailey A, Jiang MH, Honda K, Chen HY, Trumbauer ME, Van der Ploeg LH, Schaeffer JM, Leng G, Smith RG (1997) Somatostatin receptor subtype 2 knockout mice are refractory to growth hormone-negative feedback on arcuate neurons. Mol Endocrinol 11:1709-1717. 